
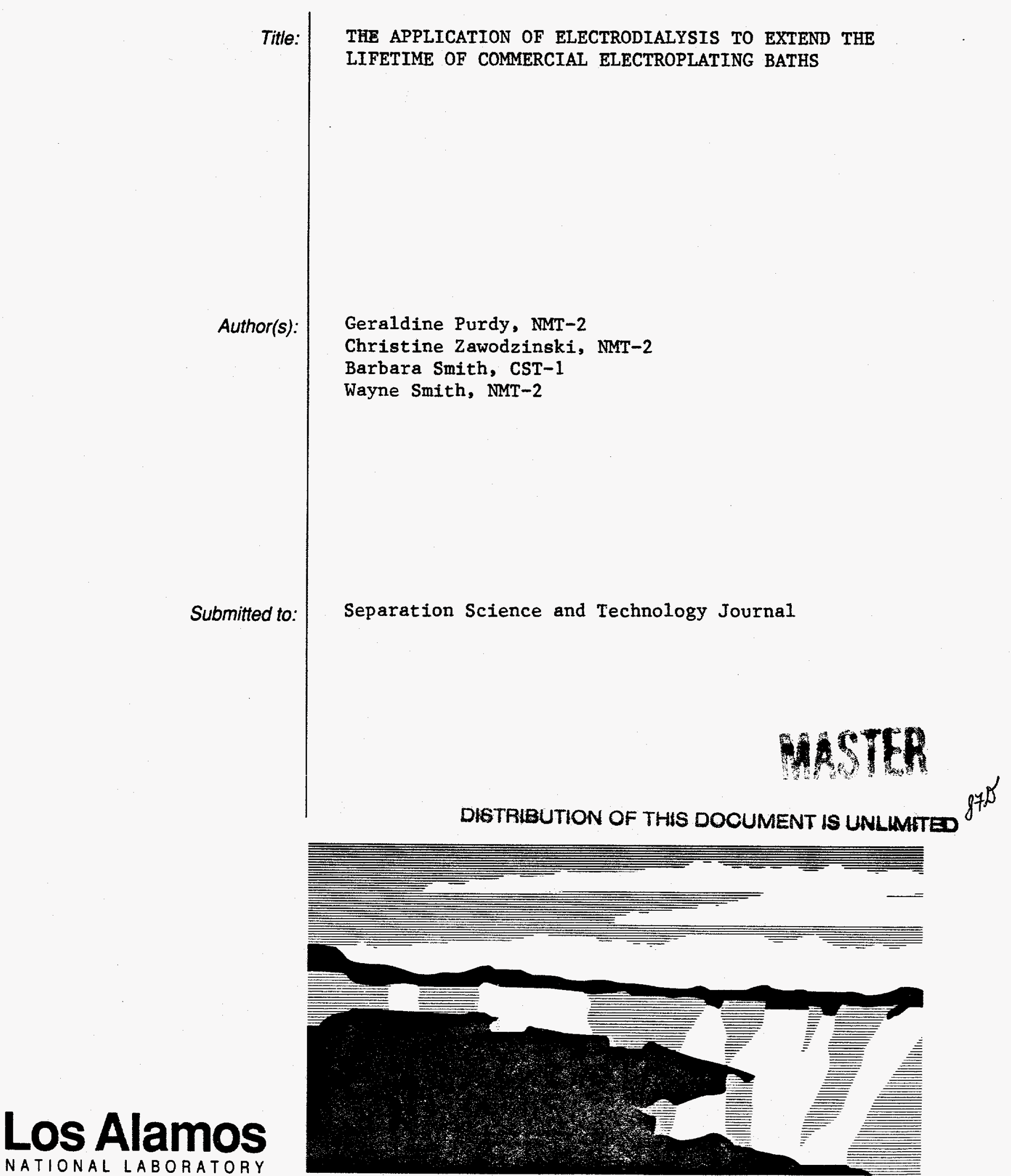

Los Alamos National Laboratory, an aftirmative action/equal opportunity employer, is operated by the University of California for the U.S. Department of Energy under contract W-7405-ENG-36. By acceptance of this article, the publisher recognizes that the U.S. Government retains a nonexclusive, royalty-free license to publish or reproduce the published form of this contribution, or to allow others to do so, for U.S. Government purposes. The Los Alamos National Laboratory requests that the publisher identify this article as work performed under the auspices of the U.S. Department of Energy. 


\section{DISCLAIMER}

Portions of this document may be illegible in electronic image products. Images are produced from the best available original document. 


\title{
THE APPLICATION OF ELECTRODIALYSIS TO EXTEND THE LIFETIME OF COMMERCIAL ELECTROPLATING BATHS.
}

\author{
Geraldine Purdy, Christine Zawodzinski, Barbara Smith, Wayne H. Smith. \\ Los Alamos National Laboratory \\ Group NMT-2, MS-E501 \\ Los Alamos, NM 87545
}

\begin{abstract}
Electrodialysis has been investigated as a method to extend the lifetime of industrial electroplating solutions via the selective removal of inert electrolyte salts that build up during electroplating operations.

The electrodialysis measurements were made using a commercially available plateand frame-type cell and various combinations of Nafion cation exchange and either Tosflex or Neosepta anion exchange membranes.

Two commercial plating solutions were studied: a zinc-tin bath in which there is a buildup of excess potassium hydroxide and a nickel-tungsten bath characterized by a buildup of excess sodium sulfate. Potassium hydroxide was effectively removed from the zinc-tin bath with very little loss of the heavy metals. Two configurations were investigated: a three compartment configuration with potassium hydroxide in the anolyte strip and sulfuric acid in the catholyte strip, and a two compartment configuration with sulfuric acid in the catholyte strip and the anode placed directly in the plating solution. In both cases potassium hydroxide was stripped from the plating solution at greater than $94 \%$ current efficiency, but at a slightly greater voltage in the three compartment cell due to increased resistance caused by the extra membrane.

A three compartment configuration was used to remove sodium sulfate from the nickel-tungsten bath, with acid solution in the catholyte and alkaline solution in the anolyte. Current efficiencies for salt removal were high but with appreciable loss of tungsten and nickel to the strip solutions.
\end{abstract}

\section{DISCLAIMER}

This report was prepared as an account of work sponsored by an agency of the United States Government. Neither the United States Government nor any agency thereof, nor any of their employees, makes any warranty, express or implied, or assumes any legal liability or responsibility for the accuracy, completeness, or usefulness of any information, apparatus, product, or process disclosed, or represents that its use would not infringe privately owned rights. Reference herein to any specific commercial product, process, or service by trade name, trademark, manufacturer, or otherwise does not necessarily constitute or imply its endorsement, recommendation, or favoring by the United States Government or any agency thereof. The views and opinions of authors expressed herein do not necessarily state or reflect those of the United States Government or any agency thereof. 


\section{INTRODUCTION}

The use of selected plating metals, such as chromium and cadmium, is becoming less desirable due to recent restrictions on the disposal of the spent plating baths and rinse solutions. There is an effort underway to replace these metals with those possessing the same desirable physical properties, but whose waste solutions are easier to treat and dispose. However it is sometimes necessary to use a binary metal system to match the physical properties of the single metal being replaced.

With a single metal system, sacrificial anodes of the metal being plated can frequently be used to replenish the metal ion in solution as it is being plated on the substrate. This can extend the useful lifetime of the bath by keeping the concentration of metal ions fairly constant.

With a binary metal plating solution this is more difficult to accomplish. Due to differences in the oxidation potential of the two metals one will dissolve preferentially relative to the other even though the anode is an alloy made in the same ratio as the relative concentration of the ions in solution. This will lead to a constantly changing ratio of metal ions in solution and also to changes in the alloy being electrodeposited.

In these cases it is necessary to use an inert electrode and maintain the correct concentration of metal ions in solution by addition of the appropriate metal ion salts. This approach can lead to a decrease in the useful lifetime of the bath due to the buildup of inert salt concentration that can limit the solubility of the metal ion salts or alter the plating characteristics of the alloy.

A potential solution to this problem is to use electrodialysis to remove the excess inert salt. Electrodialysis has been successfully used for many applications involving salt removal and on a very large scale. However for this particular application a high degree of selectivity is required since it is desirable to remove only the inert salts that accumulate in the plating bath while leaving the plating metal ion salts in the original solution.

To this end, we have investigated two binary plating solutions, a tin-zinc and a nickeltungsten bath, to determine if the inert salts could be selectively removed. 


\section{EXPERIMENTAL}

All electrodialysis experiments were carried out in either a Micro cell or MP cell (ElectroCell, Sweden). Both are of the flat plate cell design with baffles to promote turbulence at the membrane surface. Small scale experiments were conducted using the Microcell which has an effective membrane/electrode surface area of approximately 10 $\mathrm{cm}^{2}$. Feed and strip solutions of approximately $200 \mathrm{~mL}$ total volume were held in glass reservoirs and pumped through the cell using a Masterflex peristaltic pump with a speed controller to control the solution flow rates. The flow rates ranged from 2.4 to $6.0 \mathrm{~mL} / \mathrm{s}$. Larger scale experiments were carried out in the MP cell with an effective membrane/electrode surface area of $100 \mathrm{~cm}^{2}$. Three separate four liter plastic bottles were used as solution reservoirs. Typical feed and strip volumes were on the order of 2 liters. The system was also outfitted with an independent March magnetic drive pump and an EXACT rotameter for each of the three solutions to control flow rates. Flow rates were maintained at $150 \mathrm{~L} / \mathrm{hr}$.

During the electrodialysis runs, samples were removed periodically by pipet and stored for subsequent analysis. The concentration of anions in the feed and strip solutions were monitored by ion chromatography using a Dionex ion chromatograph fitted with a AS5 anion column. Nickel analysis was done by square wave voltammetry in a cyanide electrolyte solution using a Princeton Applied Research Model 384B Electoanalyzer. All other cations were analyzed by emission spectroscopy.

\section{RESULTS}

\section{Tin-Zinc}

The composition of the synthetic tin-zinc bath is listed in Table 1. The metal ion concentration is held within a fairly narrow concentration range during operation by the addition of potassium stannate and zinc oxide. The zinc oxide forms zinc hydroxide on dissolution, so excess potassium hydroxide accumulates in the bath. Removal of the 
excess reagent is accomplished by electrodialysing the plating bath in either a three compartment cell equipped with both a cation exchange membrane (Nafion 324) and an anion exchange membrane (Tosflex IE-SF34) or a two compartment cell using the single cation exchange membrane as a separator. The cell configurations, reactions and ion migrations are shown in Figure 1.

In general excess potassium hydroxide was efficiently removed from the plating

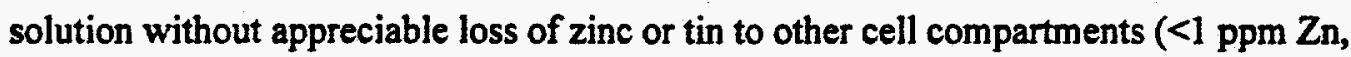
$<26 \mathrm{ppm} \mathrm{Sn}$ ). For both cell configurations the current efficiency of potassium ion removal approached $100 \%$.

The two-compartment arrangement, however, is the preferable cell configuration for electrodialysis of the zinc-tin bath for several reasons. Chemically, the excess hydroxide in the bath is neutralized directly by reaction with protons formed at the anode, eliminating the need for an anolyte strip solution and membrane to separate it from the feed. Because only one strip solution is required (for potassium ion removal), the amount of strip solution that is a byproduct of the process is decreased. Ideally the strip solution would be a useful product or be recycled for further use. With only one membrane in use, the electrical resistance in the cell is lowered. In turn the cell voltage is lowered by 2 $V$ or more at low current densities. In a small system such as ours, the energy inputs and costs which are directly affected by the cell voltage are negligible but become significant if the process is scaled up to pilot or full scale operation. The lower the cell voltage, the less energy consumed to achieve a set level of salt removal, the lower the operating cost.

Using the two-compartment cell, the effect of current density was investigated. Increasing the current density from $40 \mathrm{~mA} / \mathrm{cm}^{2}$ to $100 \mathrm{~mA} / \mathrm{cm}^{2}$ did not affect the efficiency of potassium ion removal. In all cases, current efficiencies above $95 \%$ were obtained. We tried to operate at higher current densities $\left(200-500 \mathrm{~mA} / \mathrm{cm}^{2}\right)$ but experienced difficulties maintaining constant current during a nu. This is most likely due to the conductivity of the strip solution. To achieve current densities up to 100 $\mathrm{mA} / \mathrm{cm}^{2}$, it was necessary to use a catholyte solution of $0.5 \mathrm{M} \mathrm{H}^{+}$. Thus higher current densities may be achievable if the acid concentration is increased above $0.5 \mathrm{M}$. 


\section{Nickel-Tungsten}

The composition of the synthetic nickel-tungsten bath is shown in Table 2. Addition of nickel sulfate and sodium tungstate to keep the metal ion concentration within specifications results in a buildup of excess sodium sulfate.

Citric acid is a weak triprotic acid with $\mathrm{pK}$ values of 3.13,4.77 and 6.40. Addition of the diammonium salt to the bath serves two important functions. First it buffers the solution to a $\mathrm{pH}$ of about 6 . This is the lower $\mathrm{pH}$ limit of stability of the tungstate ion, and represents the mono protonated state. At lower values it becomes fully protonated and begins to form polymeric species that are resistant to electrodeposition. At a pH of 6 nickel is only sparingly soluble, precipitating as the hydroxide. However citrate is also a complexing agent that forms soluble anionic complexes with the nickel ions. Citrates second function is to solubilize the nickel ion at this $\mathrm{pH}$.

The principal speciation in the plating bath is tungsten as the tungstate anion predominantly in the monoprotonated form, $\mathrm{HWO}_{4}{ }^{-}$, nickel as a citrate complex either $\mathrm{Ni}(\mathrm{CIT})^{-}$or $\mathrm{Ni}(\mathrm{HCIT})_{2}{ }^{2-}$, and citrate as the monoprotonated dianion species, $\mathrm{HCIT}^{2-}$. With regard to selective removal of sulfate from the plating bath this speciation is much more desirable than the tungstate dianion and citrate trianion that would exist at higher $\mathrm{pH}$ values. The more highly charged species would feel a stronger attraction for the applied electrostatic field and potentially migrate at a faster rate relative to sulfate migration.

Electrodialysis of this solution was carried out in a three compartment cell with a Nafion 117 cation exchange membrane separating the feed and catholyte solutions and a Tosflex DF-34 anion exchange membrane separating the feed and anolyte solutions. The setup is presented schematically in Figure 2. Figures 3 and 4 show the distribution of ions in the feed and anolyte during the course of a typical electrodialysis run. The concentration of nickel in the feed solution decreases slightly showing that it is slowly removed from the solution. But it appears in the anolyte rather than the catholyte which means it must be in anionic form in solution as discussed above.

All of the anions present in the feed solution, sulfate, tungstate, citrate and the nickelcitrate complex, migrate to the anolyte. However, there appears to be a small degree of selectivity for sulfate over the other anions present (Table 3). Figure 5 shows the selectivity of the anion migrations as a function of current density. Enhanced sulfate selectivity is seen at lower current densities. This is probably due to decreased 
concentration gradient formation at lower current densities. If this is indeed the case then it may be possible to achieve the same sulfate selectivity at higher current densities using faster feed solution flow through the cell.

Sodium sulfate can be effectively removed from the nickel-tungsten plating bath. There is some degree of selectivity for sulfate over the other anions present in the plating solution. However because the metals in the bath are present as anionic complexes they do migrate to the anolyte at a sufficient rate as to require the treatment of the strip solution to remove the heavy metals before discharge.

Table 1. Composition of Tin-zinc Plating Bath.

\begin{tabular}{lc}
\hline Reagent & Concentration (M) \\
\hline Potassium stannate & 0.40 \\
Zinc oxide & 0.15 \\
Potassium hydroxide & 0.36 \\
Potassium sodium tartrate tetrahydrate & 0.035 \\
Sucrose & 0.00073 \\
pH & 12 \\
Sn/Zn & 2.7 \\
\hline
\end{tabular}


Table 2. Composition of Nickel-tungsten Plating Bath.

\begin{tabular}{lc}
\hline \multicolumn{1}{c}{ Reagent } & Concentration (M) \\
\hline Nickel Sulfate & 0.07 \\
Ammonium citrate, dibasic & 0.20 \\
Sodium tungstate & 0.10 \\
$\mathrm{pH}$ & 6.1 \\
$\mathrm{~W} / \mathrm{Ni}$ & 1.4 \\
\hline
\end{tabular}

Table 3. Molar Ratios of Anions in Feed and Anolyte Strip Solutions.

\begin{tabular}{|c|c|c|}
\hline \multicolumn{3}{|c|}{ Fractional Concentration (M) } \\
\hline Ion & Feed & Anolyte Strip \\
\hline Sulfate & 0.45 & 0.50 \\
\hline Citrate & 0.35 & 0.30 \\
\hline Tungstate & 0.20 & 0.20 \\
\hline
\end{tabular}


Figure .: Electrodialysis Configurations th Tin-Zinc Plating Bath Three Compartment Cell

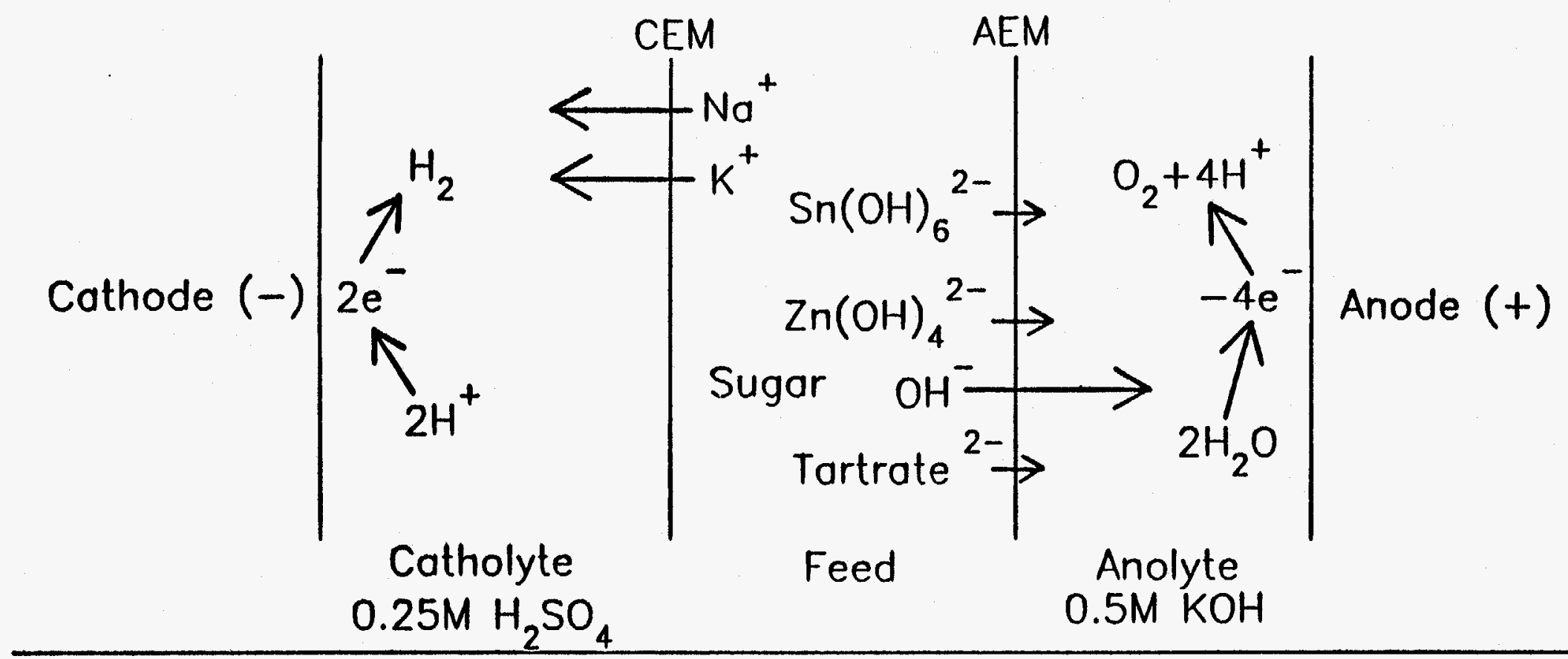

Two Compartment Cell

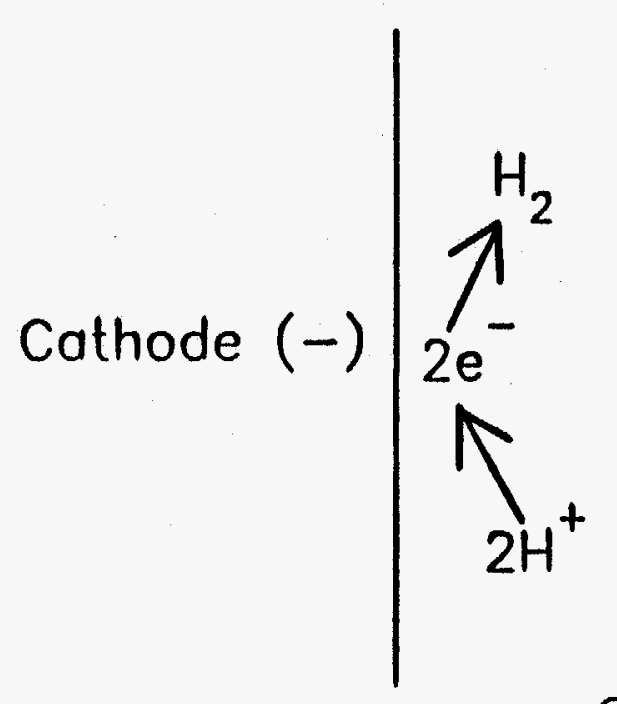

Catholyte

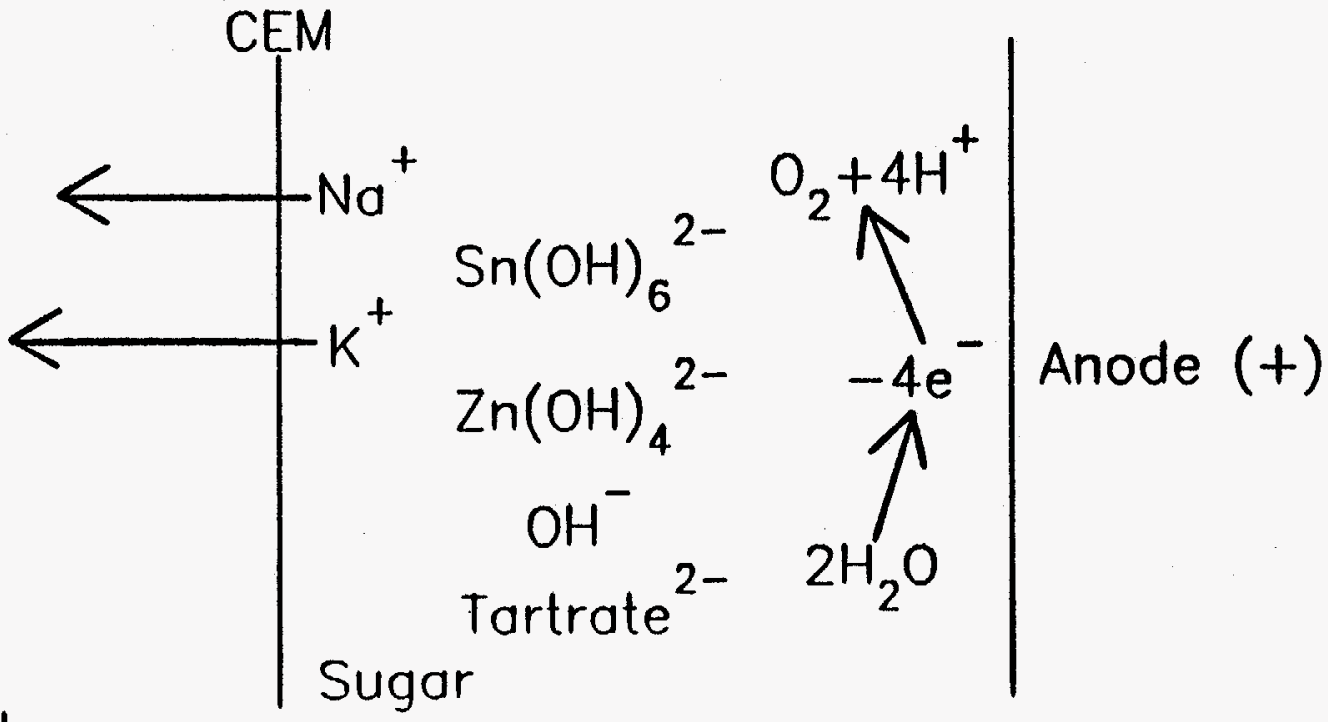

$0.25 \mathrm{M} \mathrm{H}_{2} \mathrm{SO}_{4}$

Feed 


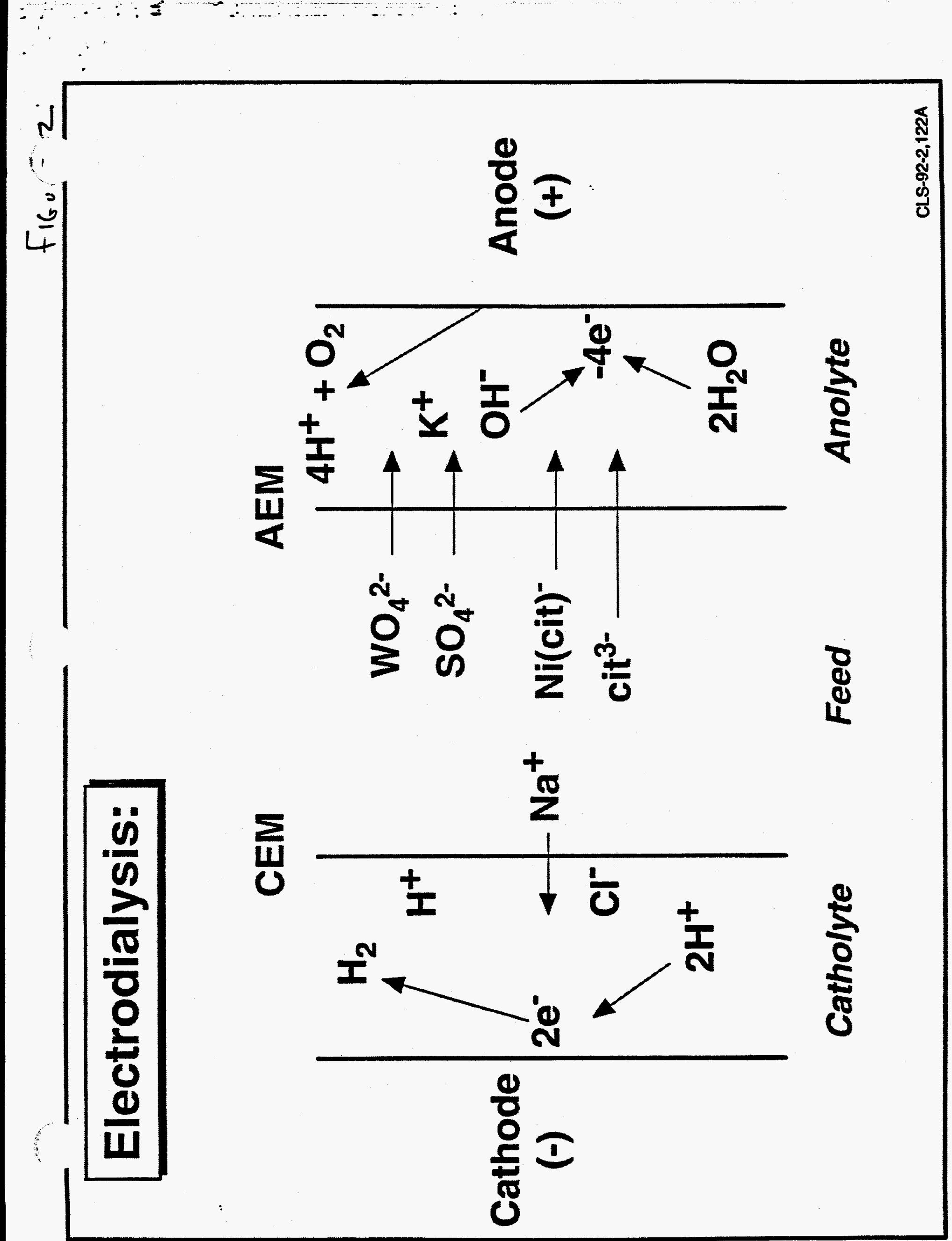




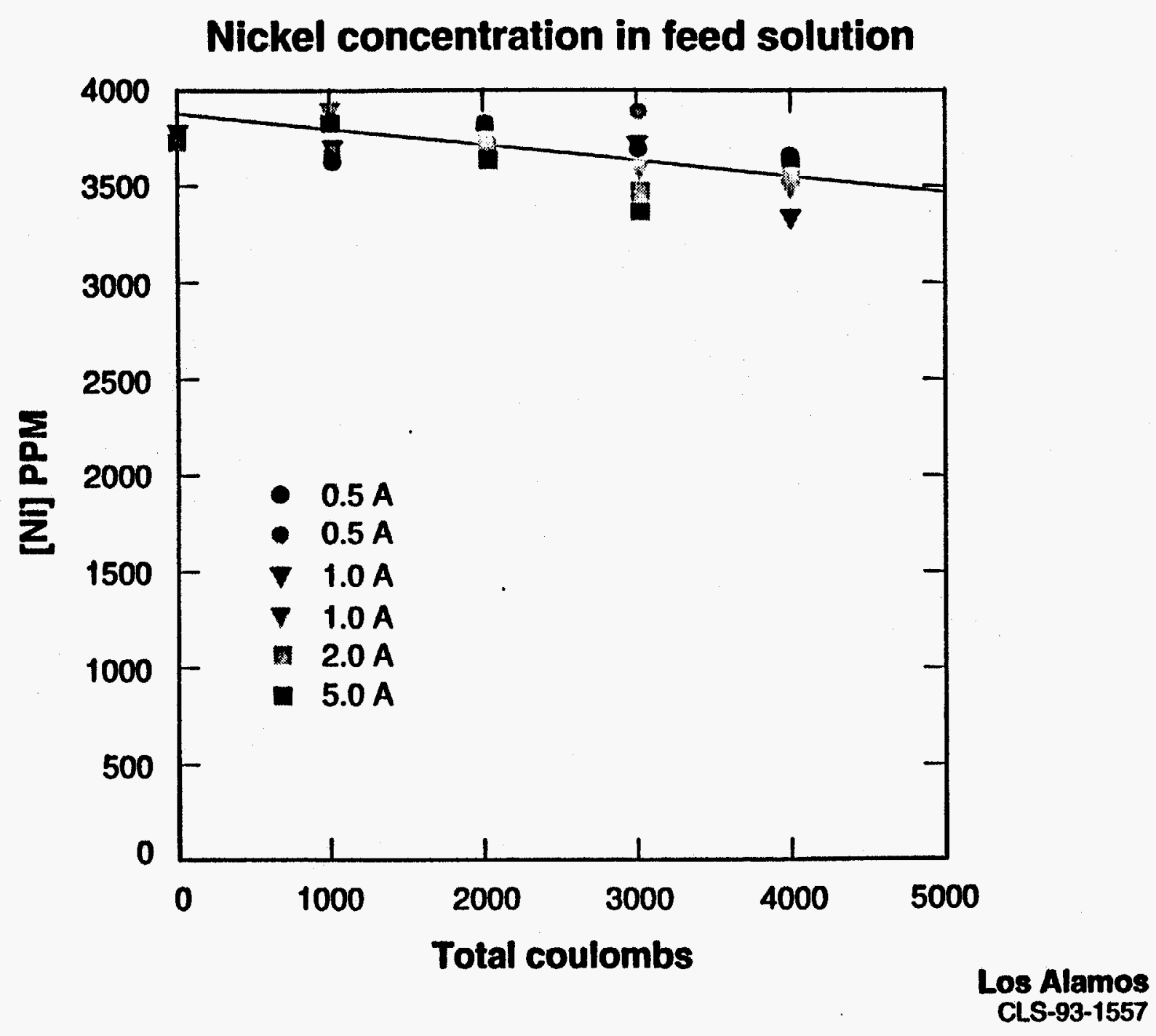


Flavel

Anolyte concentration profile

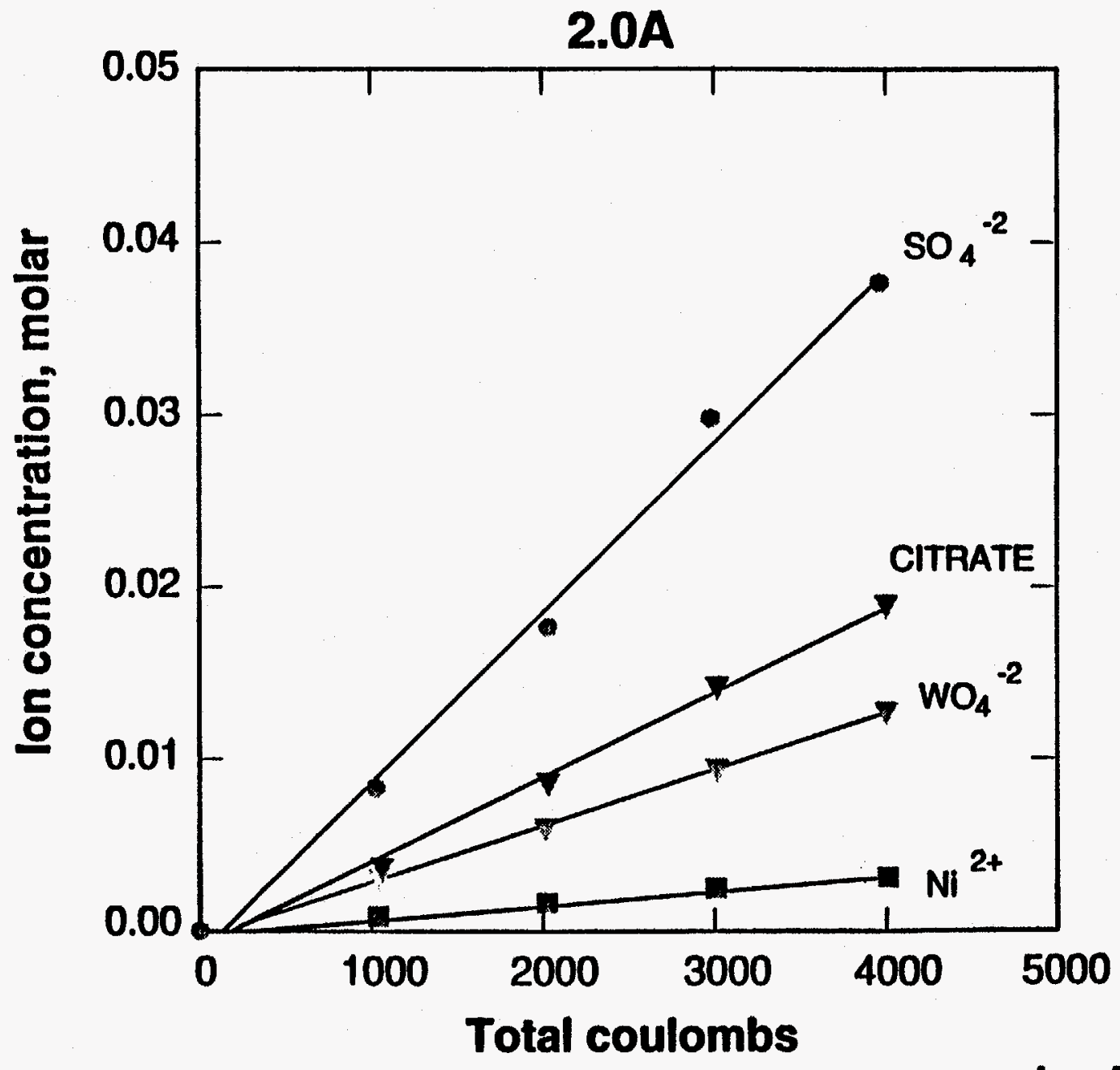

Los Alamos CLS-93-1559 
Fractional concentration of ions in the anolyte as a function of current density

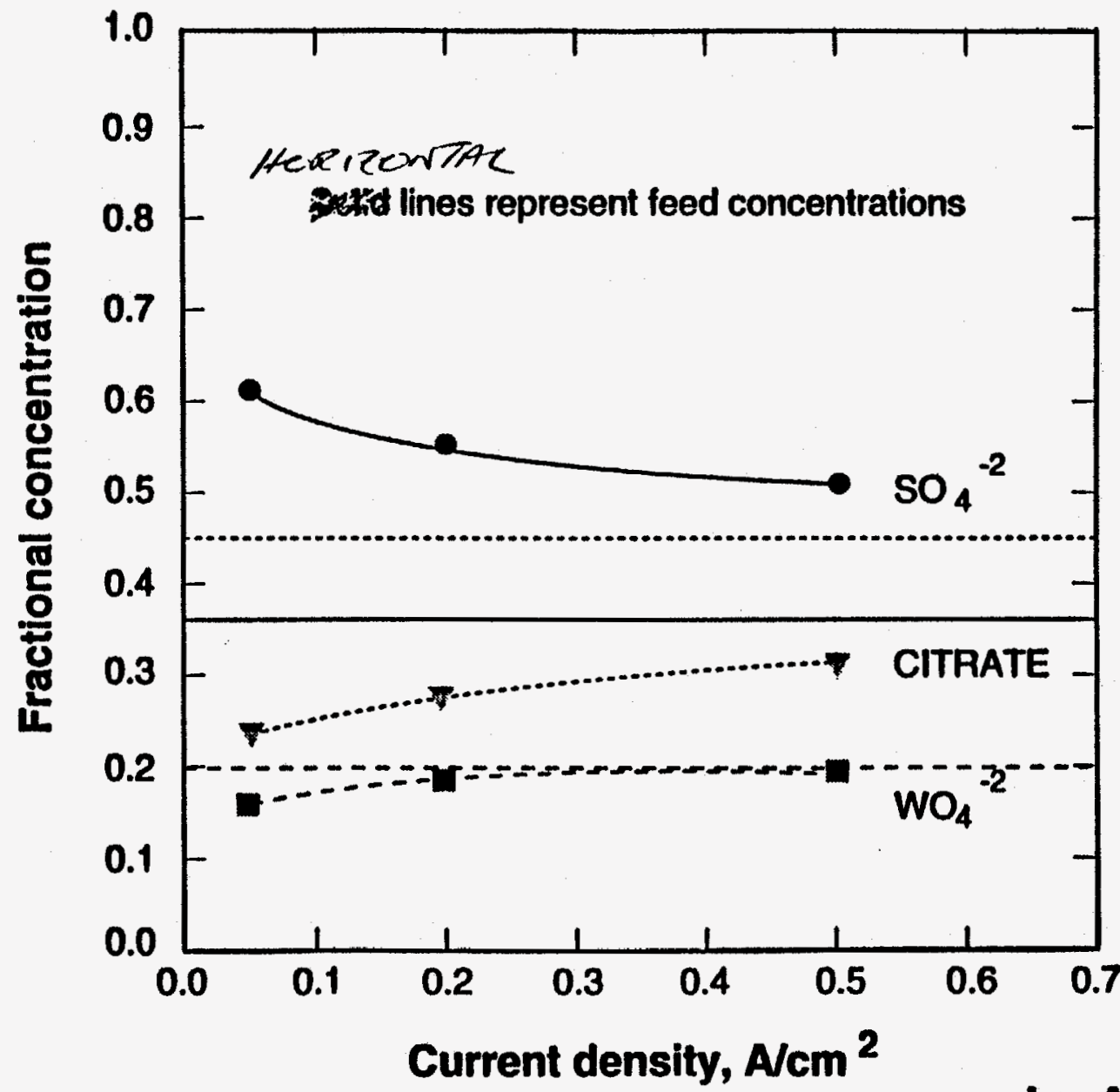

